\section{AB020. A case report on cutaneous necrotizing vasculitis treated with colchicine in a Filipino adult male}

\author{
Luisa Marie S. Cruz ${ }^{1}$, Rogelio G. Balagat ${ }^{2}$, \\ Martha B. Tapales ${ }^{2}$ \\ ${ }^{1}$ Resident, Department of Dermatology, Rizal Medical Center, Metro \\ Manila, Philippines; ${ }^{2}$ Consultant, Department of Dermatology, Rizal \\ Medical Center, Metro Manila, Philippines \\ Correspondence to: Luisa Marie S. Cruz. Department of Dermatology, \\ Rizal Medical Center, Pasig blvd. Pasig city, Philippines. \\ Email: cruzluisamarie@gmail.com.
}

\begin{abstract}
Cutaneous necrotizing vasculitis is a condition characterized by vessel wall necrosis secondary to neutrophil infiltration classically presenting as palpable purpura on the lower extremities. Several etiologic agents have been identified but, literature showed that majority of cases have an unidentifiable cause. Firstline pharmacologic management consists of systemic glucocorticoids with colchicine being used merely as second-line therapy. We report a case of a 59-year-old male with cutaneous necrotizing vasculitis treated with colchicine as monotherapy. This is the case of a 59-year-old male with a ten-day history of multiple discrete to confluent welldefined vesicles and bullae, some eroded with hemorrhagic exudates on the bilateral lower extremities, with accompanying round palpable purpura seen on the abdomen extending to the bilateral upper extremities. Skin biopsy
\end{abstract}

was consistent with leukocystoclastic vasculitis. The patient completed 3-month treatment with colchicine $500 \mathrm{mcg}$ twice daily with adjunct therapy of prednisone $20 \mathrm{mg}$ once a day for 2 weeks tapered down by $5 \mathrm{mg}$. By $4^{\text {th }}$ week of treatment, $50 \%$ improvement over the lesions were observed. By $3^{\text {rd }}$ month of treatment, complete clearance was noted. This case highlights the effectiveness of colchicine as monotherapy for cases of cutaneous necrotizing vasculitis due to its action in suppressing granulocytic inflammatory reaction. Moreover, relative safety of colchicine is more favorable compared to the possible long-term side effects of systemic glucocorticoids. Especially for patients at risk for developing adverse effects to glucocorticoids, colchicine is a feasible yet often overlooked alternative treatment option compared to the conventional treatment with systemic glucocorticoids.

Keywords: Cutaneous necrotizing vasculitis; leukocytoclastic vasculitis; small vessel cutaneous vasculitis; colchicine

doi: 10.21037/atm.2021.AB020

Open Access Statement: This is an Open Access article distributed in accordance with the Creative Commons Attribution-NonCommercial-NoDerivs 4.0 International License (CC BY-NC-ND 4.0), which permits the noncommercial replication and distribution of the article with the strict proviso that no changes or edits are made and the original work is properly cited (including links to both the formal publication through the relevant DOI and the license). See: https://creativecommons.org/licenses/by-nc-nd/4.0/.

Cite this abstract as: Cruz LMS, Balagat RG, Tapales MB. A case report on cutaneous necrotizing vasculitis treated with colchicine in a Filipino adult male. Ann Transl Med 2021;9(5):AB020. doi: 10.21037/atm.2021.AB020 